\title{
Rumo a um Sistema de Ensino Superior para Estudantes Indígenas? Universidades interculturais no México
}

\author{
Gunther Dietz' \\ Laura Selene Mateos Cortés' \\ 'Universidad Veracruzana, Xalapa - México
}

\begin{abstract}
RESUMO - Rumo a um Sistema de Ensino Superior para Estudantes Indígenas? Universidades interculturais no México. No México surgiu, a partir de 2003, um subsistema universitário alternativo explicitamente voltado para estudantes indígenas. Neste artigo examinamos criticamente as assim-chamadas universidades interculturais como um novo tipo de instituição de ensino superior. A análise foi feita por meio de pesquisa empírica oriunda de diferentes estados da arte, de nosso próprio projeto de pesquisa colaborativa-etnográfica realizado em Veracruz e de seminários interinstitucionais organizados anualmente sobre universidades interculturais. Nossa análise aponta tensões e contradições compartilhadas, mas também identifica diferentes tipos de universidades interculturais. Concluímos com algumas recomendações para políticas de ensino superior intercultural no México e na América Latina.

Palavras-chave: Multiculturalismo. Educação Intercultural. Ensino Superior Intercultural. Estudantes Indígenas. México.
\end{abstract}

ABSTRACT - Towards a Higher Education System for Indigenous Students? Intercultural universities in Mexico. In Mexico, since 2003 an alternative university subsystem explicitly directed towards indigenous students has been emerging. In this article, we critically analyze these socalled "intercultural universities" as a new kind of higher education institution, through empirical research from different states of the art, from our own collaborative-ethnographic research project carried out in Veracruz and from annually organized, inter-institutional seminars on intercultural universities. Our analysis pinpoints shared tensions and contradictions, but also identifies different types of intercultural universities. We conclude with some recommendations for intercultural higher education policies in Mexico and Latin America.

Keywords: Multiculturalism. Intercultural Education. Intercultural Higher Education. Indigenous Students. Mexico.

Educação \& Realidade, Porto Alegre, v. 46, n. 4, el16232, 2021. 
Rumo a um Sistema de Ensino Superior para Estudantes Indígenas?

\section{Introdução}

Ao longo de séculos, as relações entre grupos indígenas e as instituições de estados-nação latino-americanos têm sido tensas e contraditórias. Estas tensões e contradições podem ser identificadas desde o começo da expansão colonial europeia, mas foram sucessivamente transformadas sob os paradigmas em mudança que governavam a autoimagem e a identidade dos colonizadores e de seus descendentes em cada era histórica. As políticas nacionais resultantes, agrupadas sob o conceito polissêmico de indigenismo, encontraram no campo educacional uma de suas principais esferas de intervenção político-cultural e uma de suas ferramentas de governo mais eficazes (López; Sichra, 2016).

Contudo, ao mesmo tempo, o campo educacional também ofereceu aos atores, organizações e movimentos indígenas meios de identificação, mobilização e articulação com outros atores de suas respectivas sociedades nacionais. Desta maneira, a partir dos primeiros experimentos coloniais de reassentamento forçado em congregações até alcançar as medidas de "aculturação seletiva" (Aguirre Beltrán, 1957) do indigenismo do século XX e seus primeiros projetos de uso do ensino bilíngue transitório para reforçar a hispanização, com o uso monolíngue do espanhol como o único idioma de ensino, as políticas educacionais desenhadas desde cima e de fora especificamente voltadas para povos indígenas se tornaram uma faca de dois gumes: constituem imposições discriminatórias e, simultaneamente, criam oportunidades políticas para reivindicações e mobilizações indígenas (Dietz, 2004; Cortina, 2014).

Esta ambiguidade intrínseca de programas educacionais para povos indígenas fica explícita no começo do século XXI, quando foi estabelecida uma alternativa em diversos países latino-americanos, a assim-chamada educação superior intercultural. Trata-se de um subsistema emergente de fortes reminiscências indigenistas que surgem na interface entre estado-nação, organizações indígenas, instituições acadêmicas e atores governamentais e não-governamentais que, em cada contexto, modelam o respectivo sistema educacional nacional. Estas iniciativas de ensino superior ressoam com experiências anteriores na educação básica oferecida pelo estado-nação para comunidades indígenas, experiências essas que evoluíram para subsistemas nacionais e regionais diversos daquilo que foi, a seguir, chamado de educação indígena, educação bilíngue-bicultural e, atualmente, educação bilíngue ou multilíngue intercultural (Hornberger, 2009; Cortina, 2014; López, 2020). Da mesma forma, a educação superior intercultural reflete outra vez as tensões e contradições que transcendem a esfera educacional e que afetam a política identitária dos atores envolvidos.

Neste artigo, estas universidades interculturais (UIs) no México são apresentadas e analisadas em seus aspectos específicos como um sistema ou subsistema de educação superior emergente. Constituem uma das principais e mais inovadoras respostas institucionais que o estado-nação mexicano revelou desde o início do milênio, respon- 
dendo a reivindicações de cobertura e pertinência ao ensino superior que os povos indígenas e suas organizações vem expressando desde as décadas de 1980 e 1990․ Seguindo-se à diferenciação de três tipos de iniciativas de educação superior intercultural, nossa análise identifica algumas das principais características do ensino superior pelas quais as UIs estão começando a transformar as relações entre universidades, juventude indígena e suas comunidades: novos tipos de programas de graduação transdisciplinares, a importância central atribuída pela UI ao trabalho comunitário, o papel potencialmente decolonizador desempenhado por línguas indígenas na educação superior e, por fim, os novos perfis e papeis de docentes, estudantes e egressos de UIs. Deste modo, nosso artigo contribui para explorar as características em comum, mas também as tensões e contradições que um novo sistema universitário compartilha por seu processo de institucionalização governamental "desde cima" e seu esforço para reconhecimento comunitário "a partir de baixo".

Uma UI é oficialmente definida pelo governo federal mexicano como uma instituição de ensino superior (IES) que concentra seus programas educacionais em jovens de comunidades e regiões indígenas e que está estabelecida em ou próxima a comunidades indígenas (Casillas Muñoz; Santini Villar, 2006). Estas UIs, criadas a partir de 2003 em diferentes regiões predominantemente indígenas no México, são uma novidade institucional no sistema educacional nacional que compartilha suas características com outras iniciativas latino-americanas de ensino superior para povos indígenas, mas que também reflete características específicas de políticas educacionais mexicanas. Diferentemente de outros contextos latino-americanos, em que muitas vezes organizações governamentais e não-governamentais criam e administram novas "universidades indígenas" muitas vezes projetadas pelos próprios atores indígenas, no México estas universidades recentemente criadas surgem de acordos entre os governos federal e estaduais. Da mesma forma, são IES públicas sujeitas às regulamentações, aos princípios acadêmicos e aos canais administrativos e financeiros definidos para as universidades convencionais já existentes. Embora, em alguns casos, também haja envolvimento de atores não-governamentais, a maior parte destas universidades cofinanciadas pelo governo federal e estadual está sujeita às diretrizes do Ministério da Educação Pública (Secretaría de Educación Pública, SEP) e, especificamente, de sua Coordenação Geral de Educação Intercultural e Bilíngue (Coordinación Geral de Educación Intercultural y Bilingüe, CGEIB).

As informações empíricas em que este artigo está baseado resultam de diferentes estados da arte, revisões de literatura e estudos empíricos realizados recentemente - Schmelkes, 2008; Mateos Cortés; Dietz, 2013; 2016; Mateos Cortés; Mendoza Zuany; Dietz, 2013; Guerra García, 2016; Navarrete-Cazales; Alcántara-Santuario, 2016; Rojas Cortés; González Apodaca, 2016; Tapia Guerrer, 2016; Bermúdez Urbina, 2017; 2020; Didou Aupetit, 2018; Hernández Loeza, 2018; Dietz; Mateos Cortés, 2019; e Perales Franco; McCowan, 2021 -, de dissertações concluídas na últi- 
Rumo a um Sistema de Ensino Superior para Estudantes Indígenas?

ma década - Mateos Cortés, 2011a; Barquín Cendejas, 2012; Meseguer Galván, 2013; Olivera Rodríguez, 2013; 2019; Navarro Martínez, 2016; Hernández Loeza, 2017; Huerta Morales, 2018; Lebrato, 2018; e Vargas Moreno, 2020 -, bem como da apresentação de pesquisas em andamento sobre diferentes UIs e que discutimos coletivamente em seminários interinstitucionais anuais - Research Unit of Intercultural Studies (Cuerpo..., 2016a, 2016b), Research Unit of Intercultural Studies and Direction of the Intercultural University of Veracruz (Cuerpo..., 2017) e Ramos Calderón (2018). Ao longo destes seminários, identificamos uma ampla variedade de pesquisas atualmente realizadas por diferentes atores - estudantes, docentes e pesquisadores tanto de universidades interculturais como de outras IESs, agências de desenvolvimento e órgãos avaliadores. Esta síntese sobre as tensões e as contradições que as UIs mexicanas enfrentam está embasada nas análises e avaliações críticas formuladas nestes seminários anuais, tendo sido complementadas e comparadas com nossa própria pesquisa etnográfica-colaborativa, desenvolvida no projeto Dialogues of knowledge, action and power between academic and community actors: a reflexive ethnography of intercultural higher education in Veracruz [Diálogos de conhecimento, ação e poder entre atores da academia e comunitários: uma etnografia reflexiva da educação superior intercultural em Veracruz] (InterSaberes) ${ }^{2}$, que realizamos entre 2007 e 2017 com uma equipe de professores, estudantes e egressos da Universidad Veracruzana Intercultural (UVI) ${ }^{3}$.

\section{Universidades interculturais mexicanas públicas: 0 "modelo oficial"}

IESs novas e alternativas, muitas vezes concebidas em universidades latino-americanas e indígenas, foram descritas, analisadas e definidas por Mato $(2009 ; 2018)$ como "instituições de ensino superior interculturais”: são IESs que nascem com uma forte vocação regional e rural e que são criadas em regiões que historicamente estavam à margem da educação superior ocidental (Dietz, 2017). Em comparação com instituições educacionais convencionais, as UIs surgiram com uma dupla missão: por um lado, uma missão quantitativa de aumentar a cobertura do ensino superior para regiões rurais; por outro, uma missão qualitativa de oferecer uma graduação alternativa, não convencional e não urbanocêntrica por meio de cursos que sejam "cultural e linguisticamente relevantes” em seus respectivos contextos.

Este duplo objetivo de cobertura e relevância gera tensões no manejo político e acadêmico em cada UI - muitas vezes terminam oscilando entre uma política quantitativa de "aumento de cobertura" - números de matrícula estudantil -, e uma política qualitativa de relevância - oferecer cursos que gerem alternativas profissionais em nível local e regional além da expectativa comum entre os jovens de emigrarem de suas comunidades quando concluem seus estudos. Os objetivos de cobertura e relevância revelam, simultaneamente, a origem híbrida destas novas universidades mexicanas: surgem como parte do ciclo de políti- 
cas neoliberais de educação, fortemente condicionadas pelo paradigma da Nova Gestão Pública e por aquilo que Shore e Wright (2015) denominaram de "governar por números". Ao mesmo tempo, constituem um momento histórico de transição do indigenismo clássico integracionista do estado-nação para um multiculturalismo neoliberal (Hale, 2006) de gestão do reconhecimento e da diversidade. Isso responde à mobilização indígena e reivindica um ensino que supere a assimilação e desenvolva línguas, conhecimento e visões indígenas de mundo no ensino público da educação infantil ao ensino superior (Hernández Loeza, 2018).

No contexto destas lutas, o surgimento público do Ejército Zapatista de Liberación Nacional (EZLN) em Chiapas em 1994, e as demandas associadas por uma nova relação pós-indigenista entre o estado-nação mexicano e os povos indígenas facilitaram e aceleraram a proposta de criação de novas instituições educacionais cultural e linguisticamente relevantes para mais de sessenta grupos linguísticos e povos indígenas do México (Dietz, 2012a; 2012b; 2017). Por fim, após as eleições presidenciais de 2000, o novo governo federal reconheceu oficialmente a "educação intercultural e bilíngue" como uma prioridade política, embora não tenha reconhecido as reivindicações por autonomia indígena. Em consequência, a partir de 2003 foram rapidamente criadas novas IESs nas principais regiões indígenas do México, assim constituindo um novo subsistema universitário articulado em sua própria rede universitária, a Associação Nacional de Universidades Interculturais. Todas elas resultam de acordos bilaterais entre governo federal - através da CGEIB - e respectivos governos estaduais. Assim, foram fundadas UIs em 2004 na região Mazahua do Vale do México (Universidad Intercultural del Estado de México), em 2005 na região Chol de Tabasco (Universidad Intercultural del Estado de Tabasco) e na cidade multiétnica de San Cristobal de las Casas em Chiapas (Universidad Intercultural de Chiapas), em 2006 na região Nahua e Totonaca da Sierra Norte de Puebla (Universidad Intercultural del Estado de Puebla), em 2007 na região Maia da península de Yucatán (Universidad Intercultural Maya de Quintana Roo), na montanha Nahua de Guerrero (Universidad Intercultural del Estado de Guerrero) e na região Purhépecha de Michoacán (Universidad Intercultural Indígena de Michoacán), em 2011 em diferentes comunidades e regiões de San Luis Potosí (Universidad Intercultural de San Luis Potosí) e, por fim, em 2012, na região Hñähñu (Otomí) de Hidalgo (Universidad Intercultural del Estado de Hidalgo $)^{4}$. De acordo com uma base de dados gerada por Ramos Calderón (2018), em 2016 havia um total de 102.076 estudantes matriculados nestas universidades.

Além destas universidades recentemente criadas, há IESs já existentes que se agregaram ao programa federal, como no caso da mais antiga iniciativa de ensino superior indígena no país, a Universidad $A u$ tónoma Indígena de México, situada na região Yaqui e Mayo em Sinaloa, que foi fundada em 1982 e se juntou em 2005 à rede financiada pela CGEIB, uma rede que atualmente compreende onze UIs públicas. 
Rumo a um Sistema de Ensino Superior para Estudantes Indígenas?

O subsistema de UIs é regulado pela SEP e conduzido pela CGEIB (Casillas Muñoz; Santini Villar, 2006). De acordo com seus documentos básicos, estas IESs não se identificam como universidades indígenas, mas como instituições abertas a todos os estudantes interessados que tenham origem indígena, afrodescendente ou rural que foram excluídos do ensino superior convencional urbano. Não é a etnia indígena, mas a interculturalidade e a diversidade que, de acordo com o discurso oficial, formam a base de suas atividades educacionais (Schmelkes, 2011). Mesmo quando estas universidades tendem a ter mais de $50 \%$ de estudantes indígenas matriculados, muitas vezes eles alteram sua autoidentificação no decorrer de sua trajetória acadêmica. Enquanto muitas vezes, no ensino médio não-intercultural, estes estudantes terminam por negar sua origem autóctone ou ocultar sua língua indígena, quando ingressam na UI transitam para uma autoidentificação étnica positiva não como indígenas - um termo muitas vezes percebido como depreciativo, discriminatório e/ou racista - mas como Maya, Purhépecha, Náhuatl etc. Em muitos casos, os estudantes que tinham "perdido" completamente sua língua nativa e suas origens étnicas pela migração urbana ou, em geral, através de mestizaje - transformando-se em um mestizo não-indígena, falante de espanhol - redescobrem sua tradição na universidade intercultural (Mateos Cortés; Mendoza Zuany; Dietz, 2013; Dietz, 2017).

A partir da criação da primeira UI, surgiu um debate sobre a noção de interculturalidade oficialmente empregada em seus documentos básicos. Embora a CGEIB fomente um conceito não-indígena e não-essencialista que, no discurso oficial, respeita e inclui todos os tipos de diversidade (Casillas Muñoz; Santini Villar, 2006), tanto outros docentes como ativistas destacam o caráter fortemente harmonizador e não-conflitivo da noção oficial de interculturalidade da CGEIB. Em comparação com um conceito de interculturalidade muito mais crítico e ativo, Erdösová (2011) enfatiza que a noção "funcionalista" de interculturalidade fomentada pela CGEIB borra o legado colonial de assimetrias entre o mundo ocidental e indígenas, deste modo gerando visões de mundo "minorizadas":

O conceito de interculturalidade usado no modelo educacional da CGEIB encobre uma relação desigual entre as civilizações ocidentais e as indígenas, um fato que reduz as universidades interculturais a uma modalidade educacional minoritária de baixo impacto na sociedade mexicana (Erdösová, 2011, p. 78).

Este viés harmonizador e ahistórico da noção oficial de interculturalidade, produto do multiculturalismo neoliberal que circunscreve rigidamente o indio permitido, aquele que tem permissão oficial para ser indígena (Hale, 2006), encontra-se refletido nos decretos de criação de UIs oficiais, conforme Hernández Loeza (2016, p. 114) discute em sua análise crítica destes documentos básicos: 
O simples reconhecimento legal da interculturalidade como um princípio das políticas públicas não é garantia de que as relações de dominação e opressão irão mudar, pois espelham um pesado legado colonial de racismo e imposição da lógica ocidental moderna. Neste sentido, normas como os decretos de criação da UI são apresentadas como outra limitação para o modo de vida intercultural: em vez de oferecer um lugar para o exercício dos direitos de autodeterminação e autonomia para os povos indígenas e a construção de uma sociedade pluralista, são apresentadas como estratégias de dominação política e como um instrumento de neoindigenismo etnófago [etnocida] que caracteriza os tempos neoliberais em que estamos vivendo.

Independentemente de sua "assinatura intercultural" oficial, as universidades fomentadas pela CGEIB são caracterizadas por sua origem exógena nas regiões às quais atendem. Embora no começo respondam a reivindicações feitas por organizações indígenas, autoridades municipais ou atores educacionais locais, as novas universidades são criadas "desde cima e de fora", baseadas em acordos federal-estaduais que as definem em termos legais como "instituições públicas estaduais descentralizadas”, cuja direção sofre uma forte interferência dos respectivos governos estaduais (Hernández Loeza, 2016; NavarreteCazales; Alcántara-Santuario, 2016; Dietz, 2017; Salmerón Castro, 2017; Didou Aupetit, 2018).

Devido a suas características inovadoras e sua natureza recente, as UIs da CGEIB enfrentam um longo rol de problemas administrativos, financeiros, acadêmicos e políticos. Durante seus grandes processos de tomada de decisão, negociações políticas e consultas para a escolha de regiões e comunidades em que novos campi são criados, surgiram obstáculos, rivalidades e tensões políticas entre grupos de interesse e facções (Hernández Loeza, 2016; Dietz, 2017).

As autoridades de UIs oficiais estão expostas à vontade política dos respectivos governos estaduais, o que limita a continuidade de seus projetos acadêmicos e a autonomia de suas tomadas de decisão. Conforme relembram reitores anteriores (González González; Rosado-Maio; Dietz, 2017), na maior parte do tempo suas equipes diretivas agem como uma complexa dobradiça entre o nacional e o local, mediando, por sua vez, interesses do governo estadual e a política federal, bem como entre atores estudantis, educacionais, administrativos e comunitários (Dietz, 2017).

As intromissões políticas alheias ao ensino superior intercultural, a falta de continuidade e a constante flutuação entre diretores sofridas por diversas UIs, a falta de transparência nos processos de indicação de diretores, bem como os perfis inadequados para os grandes desafios que estas instituições acadêmicas enfrentam são fatores que impactam nos processos diários de gestão da universidade, uma gestão que até hoje carece tanto de autonomia acadêmica como financeira, o que em geral outras IESs têm (Seminario IU, 2016). 
Rumo a um Sistema de Ensino Superior para Estudantes Indígenas?

\section{Em busca de alternativas ao "modelo oficial de UI"}

Além do tipo de UI governamental recentemente criado, nos últimos anos surgiram dois outros tipos de universidade intercultural. Em primeiro lugar, instituições de ensino superior novas fomentadas por organizações não-governamentais (ONGs) já existem há uma década. O Instituto Superior Intercultural Ayuuk (ISIA) é uma universidade indígena criada em 2005 na comunidade Jaltepec de Candayoc pela população Ayuuk/Mixe de Oaxaca, pela ONG Servicios del Pueblo Mixe e pelo Sistema Mexicano de Universidades Jesuítas. O ISIA oferece cursos universitários primeiramente voltados para jovens estudantes Ayuuk, mas recentemente também passou a admitir estudantes indígenas de outras regiões de Oaxaca e do México. Uma iniciativa similar originou-se em San Idelfonso Tultepec, uma comunidade Otomí/Ñ̈ñnho no estado de Queretaro; em 2009, a confluência de um movimento cooperativo, líderes comunitários locais e o Sistema Mexicano de Universidades Jesuítas mencionado conseguiu fundar o Instituto Intercultural Ñöñho (IIÑ).

Outra iniciativa não-governamental, neste caso apoiada por movimentos sociais, projetos educacionais alternativos e agências internacionais de desenvolvimento na Sierra Norte de Puebla, é a Universidad Campesina e Indígena en Red (UCI-Red), criada em 1998 em San Andrés Tepexoxuca, Puebla, com base em uma experiência anterior bem-sucedida, o Centro de Estudios para el Desarrollo Rural (CESDER). Desde então, foram criados outros projetos de UIs, semelhantes às alianças que muitas vezes abrangem atores internos e autoridades municipais, mas também ONGs externas, como no caso da Universidad Intercultural de los Pueblos del Sur (UNISUR) no estado de Guerrero e da Universidad Comunal Intercultural Cempoaltépetl (UNICEM) no município de Tlahuitoltepec Mixe em Oaxaca.

Todas estas instituições de ensino superior interculturais são independentes da SEP e da CGEIB, assim como dos respectivos governos estaduais. Seus recursos são oriundos de ONGs, cooperativas regionais, contribuições em dinheiro que os docentes obtêm diretamente da respectiva comunidade anfitriã e, ocasionalmente, de agências internacionais de cooperação. São majoritariamente sustentadas com mecanismos de tequio comunal (atividades de reciprocidade local), além de "tequio acadêmico", como é chamado o trabalho voluntário da equipe de docentes externos, visitantes periódicos, no caso do ISIA.

Além destas iniciativas independentes e não-governamentais, com a fundação da Universidad Intercultural Veracruzana (UVI) em 2005 surge um modelo alternativo que diverge do modelo oficial CGEIB, bem como de iniciativas independentes. Neste caso, a Universidad Veracruzana, uma universidade estadual pré-existente, autônoma e pública, dá início ao seu próprio programa intercultural, que opera em quatro campi principais, cada um localizado em uma comunidade indígena nas regiões de Veracruz de Huasteca, Totonacapan, Sierra de Zongolica e Selvas e, atualmente, constitui uma UI sediada em uma universidade convencional. Com este desenho, a UVI não depende do governo 
estadual nem federal, mas desfruta da mesma autonomia que qualquer outra IES pública no México. Recentemente, outras universidades convencionais estabelecidas tanto na Cidade do México como em estados com regiões indígenas passaram a se interessar por aplicar este terceiro modelo alternativo com a finalidade de criar programas interculturais em suas próprias instituições.

\section{Programas educacionais oferecidos em UIs}

Embora nem as UIs não-governamentais nem aquelas autônomas públicas sofram restrições referentes ao projeto e ao desenvolvimento de seus currículos e disciplinas, as UIs oficiais precisam estar em íntima coordenação com a CGEIB para gerar sua oferta educacional. Desde o começo de suas atividades, as limitações da CGEIB impediram que as novas IESs governamentais oferecessem programas educacionais que "competissem" com aqueles das universidades convencionais existentes. Apesar do tipo de universidade, devido ao seu embasamento em todos os três tipos de UI, enfrentam o desafio de desenhar programas acadêmicos completamente novos que pretendam estar adaptados ao contexto local em termos linguísticos e culturais e que também reflitam a situação econômica e o mercado de trabalho regional.

Para alcançar esta finalidade, houve um esforço para evitar o viés indigenista que anteriormente limitava e conduzia o fomento de jovens profissionais indígenas apenas para profissões de cunho pedagógico ou agrícola. Esta situação persiste em muitas regiões indígenas e resulta da prioridade atribuída pelo estado-nação ao indigenismo para formar seus próprios mediadores culturais nas regiões indígenas, como contrapartida a projetos de desenvolvimento integracionistas liderados pelo estado de cima para baixo. Atualmente, estas profissões estão em crise, pois a retirada neoliberal das agências estatais das regiões indígenas cancelou estes empregos, que foram quase completamente substituídos por "técnicos" flexíveis, subcontratados de maneira precária e por projeto para medidas de assistência temporária para alívio da pobreza.

Por outro lado, os cursos que algumas IESs técnicas, pedagógicas ou agrícolas convencionais têm oferecido no México rural não estão explicitamente focadas em necessidades locais ou regionais, nem em particularidades culturais e linguísticas de seus estudantes. Neste sentido, tendem para empregos urbanos, (agro-) industriais ou de serviços, um perfil de estudos que não está adaptado à empregabilidade local e, com isso, apenas aumenta a pressão migratória que os estudantes enfrentam para encontrar emprego fora de sua região de origem. Com o objetivo de se contrapor a esta histórica drenagem rural-urbana de cérebros, e em íntima relação e com apoio explícito da CGEIB, em todas as regiões as UIs oficiais sempre começaram com dois bacharelados: um intitulado na maioria delas, "Língua e Cultura", fortemente influenciado pela tradição acadêmica mexicana de antropologia e linguística aplicada, focada na revitalização da língua e de iniciativas culturais, e 
Rumo a um Sistema de Ensino Superior para Estudantes Indígenas?

outro denominado "Desenvolvimento Sustentável", dedicado à produção rural, ecologia e conservação.

Desde o princípio, porém, ambos os bacharelados sofriam de um perfil bastante vago com relação à empregabilidade em campos profissionais específicos: o bacharelado em Língua e Cultura tem fortes reminiscências temáticas e metodológicas dos currículos convencionais para professores bilíngues de ensino básico, mas seus egressos não conseguem competir em termos semelhantes por vagas de docência com alunos das escuelas normales, instituições mexicanas tradicionais de formação de professores, que na administração federal atual estão recuperando seu privilégio histórico de conseguir "garantir" aos seus próprios egressos a preferência em empregos por escolas públicas mexicanas. Entrementes, o bacharelado em Desenvolvimento Sustentável reflete a longa tradição de programas de extensão rural de desenvolvimento e agronomia prevalentes no México até a mudança neoliberal, mas não confere a seus egressos o status profissional de um engenheiro agrícola.

Independentemente do perfil de egresso bastante difuso, outra fragilidade das disciplinas das UIs consiste na maneira como estes programas são desenhados. Nenhuma UI governamental realizou qualquer processo público de consulta "prévia, livre e informada”, conforme exigem os padrões internacionais de direitos humanos dos indígenas (Mato, 2018). Em várias UIs, foi implementado um diagnóstico interno e preliminar de necessidades educacionais locais e regionais, mas a participação dos atores da comunidade e de suas organizações indígenas foi muito escassa.

A falta de vontade de consultar abertamente as necessidades e aspirações educacionais dos jovens indígenas e de suas famílias reflete de algum modo, outra vez, as tensões mencionadas entre acesso e cobertura, por um lado, e relevância cultural e linguística por outro. Estas tensões são aprofundadas pelo fato de que, em muitas regiões indígenas do México, as demandas locais exigem que o ensino superior não inclua "disciplinas interculturais", mas sim graduações convencionais em direito, medicina, enfermagem, pedagogia etc. - demandas que contrastam com a percepção das prioridades da CGEIB para bacharelados interculturais. Estes cursos foram desenhados com expertise antropológica e linguística que leva em conta critérios de pertinência cultural e de língua regional, mas sem a participação de partes interessadas indígenas locais. Os cursos resultantes, e particularmente suas designações não convencionais, foram mal compreendidos pelos atores em nível local e, em consequência, demonstraram não ser atraentes para jovens das comunidades supostamente beneficiárias.

Não apenas as UIs públicas, dominadas pela CGEIB, mas também as iniciativas universitárias não governamentais enfrentam este mesmo desafio: docentes e pesquisadores da academia e formuladores de políticas, em um caso, e coordenadores de ONGs e intelectuais indígenas no outro, têm dificuldades em comunicar aos seus possíveis beneficiários as vantagens de currículos cujos nomes, conceitos fundamen- 
tais e perfis profissionais parecem estranhos e externos aos mundos da vida de famílias camponesas indígenas que lutam pela sobrevivência econômica e pela mobilidade social ascendente, o que em suas comunidades está intimamente relacionada a programas convencionais, não a currículos interculturais.

Como uma solução intermediária, a maioria das UIs, tanto aquelas pertencentes à CGEIB como outros tipos, foi desenvolvendo e experimentando uma gama mais ampla de bacharelados e currículos, abrangendo cursos interculturais como Língua e Cultura, Comunicação Intercultural, Gestão Intercultural para Desenvolvimento e Desenvolvimento Sustentável. Porém, cada vez mais incluem bacharelados mais convencionais, como Administração de Negócios, Governo Local, Computação, Turismo Rural etc. Ultimamente tem havido um incremento em novos bacharelados híbridos que combinam abordagem intercultural com domínio profissional específico, como no caso de Saúde Intercultural e Direito Intercultural (Schmelkes, 2008; Dietz, 2017; González; González; Rosado-May; Dietz, 2017).

\section{Trabalho comunitário como política de identidade das UIs}

Diferente de muitos bacharelados tradicionais, os cursos oferecidos e desenvolvidos em UIs têm uma característica em comum, um marcador identitário compartilhado: desde o início, no primeiro semestre de cada curso, é estabelecida uma estreita relação entre processos de ensino-aprendizagem em sala de aula, por um lado e, por outro, atividades de trabalho comunitário fora de sala de aula, preferencialmente realizadas na comunidade de origem dos estudantes. Embora muitas vezes sejam empregados métodos de ensino muito convencionais em sala de aula, diversos docentes de UIs inovam seus métodos de ensino ao combinarem aprendizagem cooperativa por meio de projetos, o que superam as limitações tradicionais de matérias ou disciplinas, com atividades práticas "de campo" na comunidade anfitriã da UI ou outras localidades próximas ao campus local.

Como estes projetos estudantis não se limitam a atividades de um semestre, mas constituem o núcleo de um processo maior de pesquisa e intervenção que, no fim, culmina no trabalho de conclusão do bacharelado, estas atividades de campo alimentam os assim-chamados "projetos integradores" ou "portfolios" de ligação com a comunidade. Em muitas UIs, formam os estudantes em um itinerário de métodos diversificados e complementares, particularmente de pesquisa-ação, que permitem o desenvolvimento de um processo de elaboração do trabalho final que não se limite aos últimos um ou dois semestres, como ocorre na maior parte das universidades convencionais. Por intermédio de métodos de diagnóstico local e regional, desenho do projeto, implementação e avaliação etc., os estudantes realizam sua própria pesquisa ao longo do curso inteiro, experimentando assim, na prática, um longo rol de métodos, técnicas e processos relacionados ao desenvolvimento comunitário e à pesquisa-ação. Ao mesmo tempo, alimentam seus 
Rumo a um Sistema de Ensino Superior para Estudantes Indígenas?

projetos com conteúdos acadêmicos que sejam flexíveis e projetados "indutivamente" para complementar o itinerário metodológico entre semestres.

No começo, os atores locais com quem as UIs lidam com frequência no trabalho comunitário são oriundos das próprias famílias e vizinhos dos estudantes em suas comunidades, mas estas redes são então expandidas e diversificadas durante todo o curso para outras partes interessadas locais ou regionais, como autoridades locais, agrárias ou religiosas, ONGs ativas na respectiva região, instituições e agências governamentais e, em alguns casos, iniciativas do setor privado.

O principal problema deste tipo de trabalho comunitário centrado no estudante, que é por si mesmo uma característica inovadora e importante das UIs e por nós identificado em vários projetos de pesquisa e seminários acima mencionados, é a falta de continuidade e a dependência da UI das redes dos próprios estudantes. Muitas UIs contam apenas com as redes destes alunos, que são sempre limitadas em tempo e escopo, impedindo assim que a universidade estabeleça colaborações estáveis de longo prazo com suas comunidades e organizações circunjacentes.

Deste modo, as UIs precisam desenvolver suas próprias políticas e estratégias específicas de colaboração com partes interessadas locais e regionais, além dos projetos individuais de seus estudantes. Muitas vezes o corpo docente e as unidades de pesquisa emergentes da UI revelam-se muito relevantes para desenhar e manter uma rede de órgãos colaborativos tanto de atores governamentais como não governamentais, de modo a ter impacto em sua comunidade anfitriã e na região à qual supostamente a UI deve atender. Desde a fundação da primeira UI, os documentos da CGEIB e o discurso oficial sempre enfatizam o trabalho comunitário como a principal característica da identidade de uma instituição intercultural. Muitas vezes, esta "política de identidade" oficial contrasta, na prática, com atividades bastante frágeis e de baixo impacto. Conforme ilustram os dados de trabalho de campo fornecidos por Hernández Loeza (2017), Huerta Morales (2018) e Vargas Moreno (2020) para o caso da UIEP, e de Navarro Martínez (2016) para o caso da UNI$\mathrm{CH}$, os atores comunitários, assim, tendem a criticar estas atividades de serviço por serem esporádicas, de curta duração e sem impacto sustentado que consiga transformar as assimetrias, desigualdades e conflitos de poder que configuram muitas regiões indígenas no México.

No entanto, também existem experiências muito positivas com a realização de trabalhos comunitários. Em algumas universidades como os quatro campi da UVI - foram criados conselhos consultivos regionais para assegurar um fluxo contínuo de informações e tomadas de decisão entre atores da academia e da comunidade. Projetos de trabalho de professores e estudantes têm desencadeado, em vários casos, um interesse local pela formulação de suas próprias prioridades de desenvolvimento em longo prazo ou buen vivir (“vida boa”) e negociá-las com a UI e suas unidades e projetos de pesquisa. Assim, atividades que 
originalmente foram concebidas e projetadas como projetos de "serviços de mão única” da universidade para a comunidade estão, agora, sendo redesenhados para incluir uma perspectiva "em mão dupla" de colaboração entre a UI e determinada comunidade local. Muitas famílias indígenas compreendem esta relação bilateral como continuada, o que inclui confiar a educação de várias gerações de seus filhos e filhas à UI. A universidade, por sua vez, mantém atividades de pesquisa e intervenção com duração mais longa juntamente com as partes interessadas locais, o que, em algumas UIs, permitiu a criação de projetos de "incubadoras" geridas pela universidade - em agricultura, ecologia, artes e ofícios, planejamento e recuperação de línguas etc. - que, mais tarde, são aplicados e transferidos às partes interessadas locais, como empresas familiares, autoridades comunitárias, ONGs e outros equivalentes. Portanto, nestas experiências, a universidade intercultural poderia, no máximo, se transformar lentamente em uma parte interessada regional de seu próprio tipo, o que ajudaria a desencadear atividades e iniciativas transformadoras muito além dos limites tradicionais do campus.

\section{O papel das línguas indígenas}

A partir dos documentos básicos, todas as UIs reconhecem o papel central que as línguas indígenas faladas em sua respectiva região devem assumir no campus para abandonar definitivamente os modelos educacionais teoricamente bilíngues do indigenismo que, na prática, têm excluído a diversidade linguística das escolas por meio de processos indiretos de hispanização. A revitalização da língua e o uso preferencial de línguas indígenas no campus estão oficialmente incluídos em todos os currículos oferecidos pelas UIs.

No entanto, a rotina diária na maioria dos campi de UIs está muito distante deste objetivo explícito de decolonizar a universidade espanhola monolíngue. Muitas vezes, o escasso uso de línguas indígenas nas UIs é desculpado pela falta de corpo docente com formação e perfil linguístico acadêmico adequado e com a competência comunicativa oral e escrita exigida. Além disso, a maior parte das UIs carece do material didático necessário em suas línguas indígenas, especialmente para conteúdos que requeiram linguagem acadêmica especializada e/ ou técnica que, atualmente, não existem na maioria das línguas indígenas. A coexistência de uma ampla variedade regional de línguas nativas e dialetos, bem como a internalização de atitudes discriminatórias e preconceitos linguísticos, adquirida e reforçada especialmente ao longo do ensino médio e superior, são também mencionadas como razões para o escasso uso de línguas indígenas. Em consequência, a maioria dos cursos está disponível apenas como programas monolíngues em espanhol, o que impede que as línguas indígenas se tornem canais de comunicação diária na UI.

A maior parte das UIs continua a usar línguas indígenas apenas para quatro objetivos limitados, os quais conseguimos identificar ao comparar experiências compartilhadas por professores indígenas de 
Rumo a um Sistema de Ensino Superior para Estudantes Indígenas?

UIs durante os seminários interanuais mencionados: primeiro, a UI identifica e classifica os estudantes em termos etnolinguísticos, o que reflete uma continuidade colonial e pós-colonial de classificar a diversidade com o uso demográfico e estatístico da língua indígena como identificador da diversidade. Segundo, as UIs oferecem uma das línguas indígenas predominantes da região como matéria curricular, transformando, assim, a língua em objeto de estudo ao invés de um meio de comunicação acadêmico. Terceiro, as UIs desenvolvem algum tipo de "ativismo linguístico-performativo" (Figueroa Saavedra et al., 2014) usando a língua indígena em momentos chave específicos, como a defesa de uma dissertação, a organização de um evento de trabalhos comunitários ou a abertura de uma cerimônia acadêmica específica. Quarto, a UI usa a língua indígena de maneira instrumental como meio de comunicação suplementar no "campo" ou em contexto de atividades comunitárias extra campus.

Pelo que sabemos, existem muito poucas experiências de transformação de uma língua indígena em um canal "normal" de comunicação acadêmica. Até agora, parece que apenas a UVI teve êxito em implementar uma estratégia de "normalização linguística" ao transformar um de seus campi, o campus Grandes Montañas situado em Tequila, na região da Sierra de Zongolica Náhuatl, em algo que não apenas todos os estudantes, mas também todo o corpo docente e de funcionários estão gradativa e conscientemente avançando para usar apenas Náhuatl como a língua diária "padrão" da UI inteira. Como um primeiro resultado deste processo de normalização da língua indígena, a UVI em Tequila recém deu início a um currículo monolíngue indígena pioneiro, o Maestriah ipan Totlahtol iwan Tonemilis, um programa de mestrado completamente oferecido e estudado em Náhuatl.

Conforme é ilustrado por esta experiência, entre outras, as línguas indígenas são elementos fundamentais para a decolonização das UIs e de ensino superior em geral. Este esforço significa avançar além dos usos parciais e muitas vezes instrumentais para canais de comunicação e construção de conhecimento genuínos. Em diversas UIs estão sendo desenvolvidas estratégias inovadoras tanto por docentes como estudantes para criar, desenvolver e fortalecer variantes acadêmicas de línguas indígenas, o que implica em processos negociados local e regionalmente de padronização, literalização e diversificação da língua. Em algumas UIs - como o campus Totonacapan da UVI (para a língua Tutunaku), o campus Las Selvas da UVI (para a língua Nuntaj+yi'), a UIEP (para a língua Ngigua), o UNICH (para a língua Zoque) e o ISIA (para a língua Ayuuk) - estão sendo iniciados cursos de redação de línguas indígenas para aquelas línguas que eram completamente orais até pouco tempo atrás. Em outros, há tentativas de padronização para aumentar a compreensão inter-dialeto entre falantes de variantes regionais do dialeto da mesma língua indígena. Em outras UIs, há iniciativas piloto para atualizar o léxico da língua indígena ao introduzir inovações semânticas que permitem aos falantes expressarem conteúdos acadêmicos em sua língua nativa. 
Estes esforços são importantes e pioneiros, mas não terão sucesso se forem alcançados apenas por determinada UI de maneira isolada de outros atores chave. Independentemente do explícito apoio por intelectuais indígenas locais e regionais, escritores, professores e suas associações, a UI precisa de uma íntima colaboração com universidades convencionais e suas escolas de idiomas: sem pesquisa linguística e diagnóstico sociolinguístico, não haverá estímulo para "reinventar" e atualizar línguas indígenas por um único esforço isolado. O desafio é ainda maior se for levado em conta que muitos jovens de regiões indígenas que concluem o ensino médio monolíngue e hispanizador estão perdendo capacidades fundamentais em sua habilidade comunicativa oral e escrita na língua nativa; tampouco adquiriram habilidades comunicativas academicamente satisfatórias em espanhol. Assim, a aquisição e o treinamento de competências de compreensão oral e escrita, bem como a escrita acadêmica em ambas as línguas representa um dos principais desafios que os estudantes de UIs enfrentam continuamente durante toda sua trajetória acadêmica.

\section{Docentes, estudantes e egressos como atores chave da UI}

Conforme as diretrizes estabelecidas pela CGEIB, o docente é caracterizado como um tutor-pesquisador que fomenta o desempenho de papeis que enunciam três ideias substanciais: ensino, pesquisa e trabalhos comunitários. Os docentes são "facilitadores da cultura entre estudantes e conhecimento" (Casillas Muñoz; Santini Villar, 2006, p. 156), pois sua tarefa consiste em desencadear processos em que os estudantes reflitam, sistematizem e capitalizem experiências comunitárias que relacionam seu conhecimento local prévio com o conhecimento "científico". Em nossa análise, identificamos que, além de reconhecer esta responsabilidade, é importante que os docentes conheçam e falem a língua de seus estudantes, algo que nem sempre ocorre.

Em termos gerais, os docentes das UIs não foram explicitamente formados para trabalhar em contextos de diversidade linguística e cultural e, sobretudo, não aplicavam estratégias de ensino intercultural até serem contratados por UIs. Isto significa que a maioria deles constrói suas estratégias didáticas a partir de suas próprias experiências profissionais anteriores, e agora está tentando articular o conhecimento e as práticas da comunidade com o conhecimento acadêmico de suas disciplinas de origem (Mateos Cortés, 2011b). Até agora, existem muito poucos programas de educação continuada intercultural visando especificamente o corpo docente de UIs.

Ainda há pouca pesquisa sobre o papel, trajetórias acadêmicas, experiências profissionais ou necessidades de formação de docentes de UIs. O que muitas vezes é enfatizado nas trocas que tivemos é a necessidade de contratar corpo docente de acordo com critérios diferentes do que em outras IESs: suas experiências de trabalho comunitário são mais importantes do que seus cursos de graduação e pós-graduação ${ }^{5}$. Um dos principais problemas enfrentados por estas instituições com 
Rumo a um Sistema de Ensino Superior para Estudantes Indígenas?

relação ao corpo docente é sua constante flutuação. Os programas de estabilidade são escassos; assim, muitos docentes terminam por sair da UI rumo a universidades convencionais reconhecidas que oferecem melhores salários, seguro-saúde e outros serviços. Esta flutuação também se deve às impressionantes tarefas enfrentadas diariamente pelos docentes que trabalham em UIs, pois devem complementar sua pesada carga de docência com atividades complementares de pesquisa, extensão ou trabalho comunitário. A carga de trabalho não docente, como pesquisa ou trabalhos comunitários, não está sendo avaliada pelas autoridades da UI. Finalmente, a flutuação do corpo docente também prejudica os processos internos necessários de consolidação de unidades de pesquisa e a vida acadêmica coletiva em cada UI.

Além dos docentes, um segundo ator chave de qualquer UI é, naturalmente, seus estudantes. De acordo com os poucos dados estatísticos disponíveis sobre matrículas em UIs, durante o ciclo 2016-2017 estas universidades atenderam aproximadamente um total de 14.784 estudantes, dos quais 55\% eram mulheres e $45 \%$ eram homens (Ramos Calderón, 2018), refletindo a tendência geral de feminização da população estudantil no ensino superior mexicano. Quase todos os alunos de UIs são estudantes de primeira geração não apenas em nível universitário, mas muitas vezes em nível de ensino médio. A maioria passou por um círculo de ensino público rural, precário, subfinanciado e, muitas vezes, de baixa qualidade composto, primeiro, por educação infantil e básica na modalidade bilíngue e, depois, por um ensino médio limitado às assim-chamadas telesecundarias e telebachilleratos (escolas de ensino médio incompleto que, devido à falta de professores, oferecem educação à distância parcialmente pela TV). Uma grande parte deles lembra, compreende ou fala alguma língua indígena embora, de acordo com números da SEP, apenas 5.284 se autoidentifiquem como falantes de línguas indígenas (Ramos Calderón, 2018).

Devido à condição de renda muito baixa de seus pais, a maioria dos estudantes tem acesso a algum tipo de financiamento por bolsa de estudos estadual ou federal para conseguir se matricular e concluir seus estudos universitários. É uma bolsa de estudos muito reduzida e que os apoia basicamente com custos de transporte entre sua comunidade e o campus e alguns materiais didáticos. Nem sempre estudar em uma UI é a primeira escolha, pois muitos terminam por se matricular nela devido à carência de recursos econômicos e à falta de acesso a outras IESs convencionais, seja porque foram reprovados em exames de seleção ou devido à sua distância linguística e/ou cultural no que diz respeito a instituições espanholas mestizo. Além disso, às vezes a escolha por estudar na universidade não é individual, mas uma decisão da família ou da comunidade. Nestes casos, a opção por uma UI significa reduzir as despesas da família com ensino superior em comparação com uma IES urbana mais distante.

Uma vez imersos na vida acadêmica da UI, os estudantes passam por transições intensas e fortemente sentidas em suas identidades, pois de repente são convidados a se relacionar com a cultura, a língua e o 
legado de sua família e comunidade, algo que precisavam esconder antes. Além disso, viver no campus também significa estar exposto a, e conseguir desfrutar de outras fontes de diversidade, como relações de gênero, diversidade sexual e religiosa e orientações de visão de mundo. A conscientização sobre racismo, sexismo e outras fontes de discriminação é explicitamente ensinada em diversas UIs, o que muitas vezes desencadeia profundos processos de redefinição pessoal, de repensar relações familiares e intergeracionais - diversos estudantes são oriundos de famílias cujos pais, reagindo à discriminação societal contra eles, os impediam de aprender sua língua nativa, o que os impossibilitava de se comunicarem com seus avós - assim como de autoestima no que diz respeito aos seus próprios projetos pessoais, comunitários e profissionais futuros.

A pesquisa realizada sobre estudantes de UIs enfatiza sua diversidade interna. Etnicamente, as transformações de identidade e os fenômenos de reetnização são destacados, o que torna impossível usar rótulos como "indígena” ou mestizo/"não-indígena” como categorias fixas (Bermúdez Urbina, 2017). Socioeconomicamente, a maioria dos estudantes é oriunda de contextos rurais e marginalizados; suas experiências com classe urbana, "média" e ambientes acadêmicos são quase inexistentes.

Quando terminam seus respectivos bacharelados, muitos egressos de UIs enfrentam um processo muito difícil de integração ao mercado de trabalho. Apesar de terem adquirido as habilidades necessárias para trabalhar em iniciativas de desenvolvimento comunitário, em projetos de revitalização da língua, em educação bilíngue, em atenção primária à saúde rural, em projetos agroecológicos sustentáveis e/ou em lutas por direitos humanos em prol de suas comunidades e territórios, a imensa maioria dos egressos não encontrará emprego de longa duração e estável em algum destes domínios profissionais. Muitos optam por serem autônomos, trabalhar em organizações cooperativas ou nãogovernamentais, mas alguns escolherão permanecer na comunidade, retornando às atividades camponesas de suas famílias e as apoiando ao diversificar colheitas, alternativas de marketing e/ou opções de financiamento.

Alguns egressos de UIs conseguiram ser contratados por instituições governamentais e, especificamente, por governos locais. Em nosso projeto InterSaberes, para o caso da UVI, a formação inter ou transdisciplinar dos egressos com projetos, seu íntimo conhecimento da tomada de decisão comunitária e estruturas organizacionais, bem como suas habilidades comunicativas multilíngues que permitem que interajam tanto por escrito como oralmente em espanhol e em línguas indígenas, são os aspectos fundamentais destacados por empregadores, entrevistados e congêneres institucionais entrevistados (Dietz; Mateos Cortés; Budar, 2020).

Contudo, muitos egressos entrevistados também mencionam diversas fragilidades em sua formação na UI. Em comparação com pro- 
Rumo a um Sistema de Ensino Superior para Estudantes Indígenas?

gramas semelhantes oferecidos em universidades convencionais, na opinião deles e em comparação com outras profissões com as quais competem, muitas vezes sentem falta de conhecimento em matemática, estatística e outros métodos quantitativos. Da mesma forma, a ênfase em tópicos antropológicos e linguísticos em muitos cursos de UIs leva a uma sub-representação de questões econômicas e empresariais e a um viés em direção às humanidades em comparação com programas técnicos, de ciências e de engenharia. Finalmente, vários egressos mencionam a necessidade de programas de pós-graduação especificamente interculturais, além de educação continuada e, em geral, de cursos e diplomas mais flexíveis, mais breves e de tempo parcial, o que também poderia ser um atrativo para profissionais já atuantes, e não apenas para jovens estudantes universitários "em tempo integral”, mas para atores comunitários como professores em exercício, enfermeiras, curandeiros, juízes e camponeses interessados em diversificar seus conhecimentos profissionais e comunitários.

\section{Conclusões e perspectivas}

Está surgindo nas universidades interculturais mexicanas uma intelectualidade indígena academicamente profissionalizada como um novo tipo de ator híbrido, pois este ator também tem um forte e evidente perfil comunitário - um tipo de estudante e egresso indígena que durante toda sua carreira universitária não foi completamente separado de sua origem indígena rural e que, no melhor dos cenários, é capaz de desencadear processos de intercâmbio de conhecimento, de novos papeis e funções que lhes permitirão subsequentemente manejar, mediar e traduzir entre mundos, entre atores e entre profissões (Mateos Cortés; Dietz; Mendoza Zuany, 2016; Mateos Cortés, 2017). No futuro, será necessário que tanto a pesquisa empírica monográfica como a comparativa acompanhem, analisem e comparem estes processos de academização, profissionalização e comunalização que os egressos de UIs estão vivencindo (Dietz; Mateos Cortés; Budar, 2020).

A análise aqui resumida de diversos projetos de pesquisa e estados da arte em UIs ilustra que estas novas IESs estão conseguindo formar jovens em seus respectivos contextos de origem rural e em novos padrões de carreira, mas que, simultaneamente, representam grandes desafios para a consolidação deste tipo de universidade. Diferenciamos três tipos de UIs que estão sendo rapidamente institucionalizados por um rol de atores diversificados: a UI governamental criada como "um modelo oficial", um modelo sob mentoria da CGEIB que depende fortemente dos respectivos governos estaduais; a UI não-governamental, que responde ao "modelo jesuíta" e que, portanto, se assemelha a uma lógica de ONG ou de fundações privadas e denominacional; e, finalmente, aquelas que partem de uma universidade pública autônoma já estabelecida, como aquela que denominamos "modelo UVI". Portanto, agora é preciso uma pesquisa comparativa para comparar e avaliar as vantagens e desvantagens de cada um destes tipos de UI. 
Da mesma forma, será necessário contextualizar o subsistema mexicano de ensino superior intercultural no panorama latino-americano continental mais amplo, no qual - conforme mencionamos no começo - existem experiências similares, mas onde outras partes interessadas parecem ser mais influentes do que os estados-nação (Mato, 2011). É muito marcante que tanto as realizações como os desafios enfrentados por estas novas IESs em outros países latino-americanos sejam muito semelhantes àqueles que observamos aqui no caso das UIs mexicanas.

Identificamos ao longo deste artigo como o ensino superior intercultural mexicano nasceu "desde cima", mas em resposta aos vieses excludentes do sistema universitário hegemônico e às reivindicações de povos indígenas "a partir de baixo". Refletindo estas tensões entre atores governamentais e indígenas, neste artigo distinguimos primeiramente três tipos de UI: um tipo de universidade pública, criado como uma iniciativa governamental "desde cima" com fortes laços com o Ministério da Educação e governantes estaduais; uma UI não-governamental, "privada", é independente de atores governamentais, mas que se baseia em ordens religiosas ou em cooperação internacional de desenvolvimento como agências financiadoras; e uma UI patrocinada e dirigida como uma "filial intercultural" de dentro de uma universidade pública autônoma. Enfatizamos que - apesar destas origens e restrições diversas - os três tipos de UI enfrentam desafios similares - como alternativa e subsistema de IES muito recentes lutando por reconhecimento às margens de universidades convencionais grandes e bem estabelecidas.

Entretanto, também conseguimos identificar pelo menos quatro características comuns de UIs mexicanas que ilustram um enorme potencial para inovação e transformação. Primeiro, currículos inovadores oferecidos em nível de bacharelado ou de pós-graduação para jovens indígenas em suas regiões rurais e altamente marginalizadas de origem não "exportam" nem replicam cursos e graduações convencionais, de natureza disciplinar, orientação curricular voltada para a aprendizagem enciclopédica e mecanizada, bem como sua tendência para opções de emprego urbano; ao contrário, os cursos inter e transdisciplinares que combinam aprendizagem teórica em sala de aula e fases de aprendizagem prática, aplicadas fora do campus e na comunidade contribuem para educar a juventude indígena como mediadores e tradutores entre tradições e fontes diversas de conhecimento.

Em segundo lugar, as UIs se identificam explicitamente com trabalhos comunitários como função central de uma IES: estudantes, docentes e a instituição como tal fomentam uma vocação para relações comunidade-universidade através de uma cultura que não concebe esta relação como unidirecional; os atores da UI não apenas "prestam" serviços para suas comunidades circunvizinhas, mas estas tendem a se transformar em oportunidades de aprendizagem de mão dupla tanto para estudantes como docentes, por um lado, e anciãos e anciãs e autoridades locais, por outro. Assim, o trabalho comunitário faz parte do 
Rumo a um Sistema de Ensino Superior para Estudantes Indígenas?

currículo de ensino e das atividades de pesquisa, em vez de ser marginalizado como uma atividade isolada e suplementar da universidade.

Em terceiro lugar, as línguas indígenas são incorporadas de maneira lenta, mas irreversível ao ensino, aprendizagem e atividades de trabalho comunitário da UI. Apesar de sua criação recente, as UIs estão se tornando líderes em políticas de línguas alternativas, no planejamento de línguas comunitárias e no desenvolvimento de currículos multilíngues. Como é mostrado acima, este processo de "normalização linguística" tem um importante efeito decolonizador: transformar uma língua indígena em um canal de comunicação acadêmica "normal" reverte as tentativas coloniais e pós-coloniais de impor instituições educacionais espanholas monolíngues. Embora o desafio seja enorme e os recursos necessários limitados, as UIs estão desenvolvendo práticas multilíngues que, em longo prazo, também terão impacto forte e desafiador para IESs convencionais não-interculturais mexicanas e latinoamericanas.

Em quarto e último lugar, o papel decolonizador das UIs não se limita à inclusão de uma língua indígena no ensino superior, mas compreende também a inclusão de novos perfis para os atores chave da universidade, como docentes e estudantes. Com a ênfase da UI em relações comunidade-universidade, em línguas indígenas e em resultados de aprendizagem orientada pela experiência e pela prática, surge um novo tipo de professor-mediador-tradutor. O conhecimento situado e relevante da comunidade ou da região, de sua(s) língua(s) indígena(s) e de costumes locais de educação, saúde, justiça, meio ambiente, produção e cosmologia indígena em geral torna-se muito mais decisivo para o ensino do que se representasse uma única disciplina determinada, um doutorado brilhante ou um registro impressionante de publicações em periódicos internacionais de alta classificação. Estes novos perfis de ensino "de baixo para cima” e orientado pela práxis são complementados por novos perfis de estudantes. Em todas as UIs do México, jovens indígenas que ingressam no ensino superior são pioneiros de primeira geração não apenas em suas famílias ou comunidades, mas em toda sua região. O fato de que agora, em cada uma destas regiões, existem egressos da universidade educados por meio de uma visão ampla e crítica de relações interculturais empodera não apenas os estudantes e suas famílias, mas também impacta suas localidades e municípios, iniciativas não-governamentais que surgem na região e, por fim, também as relações de poder entre povos indígenas e a sociedade nacional.

Com a finalidade de ajudar a aprofundar estes impactos locais e regionais, as UIs precisam de autonomia, total reconhecimento e tratamento igual em relação às IESs convencionais. Esperamos que no atual contexto mexicano, em que o governo federal está priorizando a expansão da cobertura do ensino superior para estudantes não-convencionais e determinados estudantes de origem rural, estas UIs bastante novas consigam obter autonomia e presença acadêmica para consolidar suas principais características: currículos delineados de maneira regional e contextual, que sejam interculturais indutivos e multilíngues, que 
ofereçam à juventude indígena ferramentas profissionais e comunitárias para impactar positivamente seus mundos de vida local e, assim, decolonizar as relações desiguais que suas comunidades ainda sofrem no que diz respeito aos mundos hegemônicos não-indígenas, mestizo e urbanos $^{6}$.

Traduzido do inglês por Ananyr Porto Fajardo

Recebido em 27 de junho de 2021 Aprovado em 21 de setembro de 2021

\section{Notas}

1 A seguir, sintetizamos alguns de nossos achados de pesquisa prévios apresentados em Dietz (2012a; 2012b; 2017); Mateos Cortés e Dietz (2013; 2016); e Dietz e Mateos Cortés (2019; 2020).

2 O projeto teve uma primeira fase piloto inicial (2007-2009), que foi financiada pela Diretoria Geral de Investigações da UV e pela SEP, e, mais tarde (20102014), recebeu subvenção do Conselho Nacional para a Ciência e a Tecnologia. (CONACYT, Chamada 2009 para Ciências Básicas) e da Agência Espanhola para Cooperação de Desenvolvimento Internacional (AECID, chamada para auxílio a programas de cooperação e pesquisa científica interuniversidades); em sua continuidade, atualmente (2015-2018) faz parte de um projeto mais amplo denominado "Processos emergentes e agenciamentos em comum: práxis de pesquisa social colaborativa e novas formas de subjetivação política" (Chamada 2014, projetos R\&D, programa estatal espanhol para promoção de pesquisa técnica e científica de excelência; referência: CSO2014-56960-P).

3 Dietz (2008; 2012a); Mateos Cortés (2015; 2017); Mateos Cortés e Dietz (2016); Mateos Cortés, Dietz e Mendoza Zuany (2016); Dietz e Mateos Cortés (2020).

4 Para mais detalhes, ver Dietz (2017); González González, Rosado-Maio e Dietz (2017).

5 Todas as UIs enfatizam a importância de integrar "anciãos e anciãs" e/ou intelectuais indígenas como corpo docente para reforçar o conhecimento comunitário; entretanto, até agora esta sabedoria "informal" não é considerada como qualificação acadêmica, de modo que não podem ser contratados pelas UIs, podendo colaborar apenas como voluntários.

6 Agradecimentos: Os autores agradecem a Margarita Alcántara Alemán por seu apoio ao traduzir este texto do espanhol.

\section{Referências}

AGUIRRE BELTRÁN, Gonzalo. El proceso de aculturación. México: UNAM, 1957.

BARQUÍN CENDEJAS, Alfonso. Antropología y poder político. 2012. Thesis (Doctorado en Ciencias Antropológicas) - Universidad Autónoma Metropolitana, Iztapalapa, 2012.

BERMÚDEZ URBINA, Flor M. La investigación sobre trayectorias académicas y experiencias de estudiantes en la educación superior intercultural en México. Revista Educación y Desarrollo Social, v. 11, n. 1, p. 116-145, 2017. 
Rumo a um Sistema de Ensino Superior para Estudantes Indígenas?

BERMUDEZ URBINA, Flor M. Agencia social y educación superior intercultural en Jaltepec de Candayoc, Mixe, Oaxaca. Tuxtla Gutiérrez: UNICACH - ISIA, 2020.

CASILLAS MUÑOZ, Lourdes; SANTINI VILLAR, Laura. Universidad Intercultural: modelo educativo. Mexico: SEP-CGEIB, 2006.

CORTINA, Regina (Ed.). The Education of Indigenous Citizens in Latin America. Bristol: Multilingual Matters, 2014.

CUERPO Académico Estudios Interculturales (Ed.). I Seminario de investigación Universidades Interculturales en México: balance de una década (2015): memorias. Xalapa: Universidad Veracruzana, 2016a. Available at: https://www. uv.mx/iie/files/2013/02/I-seminario-Universidades-Interculturales-Documento-de-trabajo.pdf. Accessed on: 22 dez. 2020.

CUERPO Académico Estudios Interculturales (Ed.). II Seminario de investigación Universidades Interculturales en México: balance de una década" (2016): memorias. Xalapa: Universidad Veracruzana, 2016b. Available at: https://www. uv.mx/iie/files/2013/02/II-seminario-Universidades-Interculturales-Documento-de-trabajo.pdf. Accessed on: 22 dez. 2020.

CUERPO Académico Estudios Interculturales y Dirección de la Universidad Veracruzana Intercultural (Ed.). Una década de Investigación sobre la UVI: Jornadas de presentación de resultados de investigación (2016). Xalapa: Universidad Veracruzana, 2017. Available at: https://www.uv.mx/iie/files/2013/02/JornadasUVI-2016.pdf. Accessed on: 22 dez. 2020.

DIDOU AUPETIT, Sylvie A. La educación superior indígena e intercultural en México en 2018. Revista de la Educación Superior, v. 47, n. 187, p. 93-109, 2018.

DIETZ, Gunther. From Indigenismo to Zapatismo: the struggle for indigenous rights in twentieth century Mexico. In: POSTERO, Nancy Grey; ZAMOSC, Leon (Ed.). The Struggle for Indian Rights in Latin America. Brighton: Sussex Academic Press, 2004. P. 32-80.

DIETZ, Gunther. La experiencia de la Universidad Veracruzana Intercultural. In: MATO, Daniel (Coord.). Diversidad Cultural e Interculturalidad en Educación Superior: experiencias en América Latina. Caracas: UNESCO-IESALC, 2008. P. 359-370.

DIETZ, Gunther. Diversity Regimes Beyond Multiculturalism? A reflexive ethnography of intercultural higher education in Veracruz, Mexico. Latin American and Caribbean Ethnic Studies, v. 7, n. 2, p. 173-200, 2012a.

DIETZ, Gunther. Intercultural Universities in Mexico. In: BANKS, James (Ed.). Encyclopedia of Diversity in Education. v. 3. Los Angeles: SAGE, 2012b. P. 14801484 .

DIETZ, Gunther. Introducción. In: GONZÁLEZ GONZÁLEZ, Floriberto; ROSADO-MAY, Francisco J.; DIETZ, Gunther (Ed.). La gestión de la educación superior intercultural: retos y perspectivas de las universidades interculturales. Chilpancingo: Ediciones Trinchera, 2017. P. 21-31.

DIETZ, Gunther; MATEOS CORTÉS, Laura Selene. Las universidades interculturales en México, logros y retos de un nuevo subsistema de educación superior. Estudios sobre las Culturas Contemporáneas, v. 25, n. 49, p. 163-190, 2019.

DIETZ, Gunther; MATEOS CORTÉS, Laura Selene. Between Community and University: a collaborative ethnography with young graduates from a Mexican Intercultural University. AIBR. Revista de Antropología Iberoamericana, v. 15, n. 2, p. 273-298, 2020. 
DIETZ, Gunther; MATEOS CORTÉS, Laura Selene; BUDAR, Lourdes (Ed.). La gestión intercultural en la práctica: la Universidad Veracruzana Intercultural a través de sus egresadas y egresados. Xalapa: Editorial Universidad Veracruzana, 2020.

ERDÖSOVÁ, Zuzana. La universidad intercultural latinoamericana como un fenómeno múltiple. Cuadernos Interculturales, v. 11, n. 21, p. 59-84, 2011.

FIGUEROA SAAVEDRA, Miguel et al. La incorporación de las lenguas indígenas nacionales al desarrollo académico universitario. Revista de la Educación Superior, v. XLIII, n. 3, p. 67-92, 2014.

GONZÁLEZ GONZÁLEZ, Floriberto; ROSADO-MAY, Francisco J.; DIETZ, Gunther (Ed.). La gestión de la educación superior intercultural: retos y perspectivas de las universidades interculturales. Chilpancingo: Ediciones Trinchera, 2017.

GUERRA GARCÍA, Ernesto. La Universidad Autónoma Indígena de México en sus inicios. Culiacán: INAPI - UAIM, 2016.

HALE, Charles. "Más que un indio": racial ambivalence and neoliberal multiculturalism in Guatemala. Santa Fe: SAR Press, 2006.

HERNÁNDEZ LOEZA, Sergio E. Limitadas por decreto: las restricciones normativas de las universidades interculturales oficiales en México. Revista del Cisen Tramas/Maepova, v. 4, n. 2, p. 95-119, 2016.

HERNÁNDEZ LOEZA, Sergio E. Proyectos políticos, educación superior interculturalización y modernización educativa en Ecuador y México. 2017. Thesis (Ph.D. in Estudios Latinoamericanos) - Universidad Nacional Autónoma de México, Ciudad de México, 2017.

HERNÁNDEZ LOEZA, Sergio E. Educación superior, diversidad cultural e interculturalidad en América Latina: estudio sobre México. In: MATO, Daniel (Coord.). Educación superior, diversidad cultural e interculturalidad en América Latina. Caracas; Córdoba: UNESCO; IESALC, Universidad Nacional de Córdoba, 2018. P. 225-248.

HORNBERGER, Nancy H. La educación multilingüe, política y práctica: diez certezas. Revista Guatemalteca de Educación, v. 1, n. 1, p. 95-138, 2009.

HUERTA MORALES, Ma. Guadalupe. Discursos y metáforas de política educativa a través de la Universidad Intercultural del Estado de Puebla. 2018. Thesis (Doctorado en Ciencias Antropológicas) - Universidad Autónoma Metropolitana, Iztapalapa, 2018.

LEBRATO, Matthew J. Negotiating Difference, Translating Community: Ayuuk indigenous knowledge and Mexican intercultural education. 2018. Thesis (Ph.D. in Philosophy) - Indiana University, Bloomington, 2018.

LÓPEZ, Luis Enrique. What is educación intercultural bilingüe in Latin America nowadays: results and challenges. Journal of Multilingual and Multicultural Development, 2020. DOI: 10.1080/01434632.2020.1827646.

LÓPEZ, Luis Enrique; SICHRA, Inge. Indigenous Intercultural Bilingual Education in Latin America. In: GARCIA, O.; LIN, A.; MAY, S. (Ed.). Bilingual and Multilingual Education: Encyclopedia of Language and Education. V. 5. New York: Springer, 2016. P. 381-394.

MATEOS CORTÉS, Laura Selene. La migración transnacional del discurso intercultural: su incorporación, apropiación y resignificación por actores educativos en Veracruz, México. Quito: Abya-Yala, 2011a. 
Rumo a um Sistema de Ensino Superior para Estudantes Indígenas?

MATEOS CORTÉS, Laura Selene. ¿Docentes interculturales? Un emergente actor educativo en las universidades interculturales. In: CONGRESO NACIONAL DE INVESTIGACIÓN EDUCATIVA, 11, 2011, UNAM, Ciudad de México. Proceedings... Ciudad de México: UNAM, UANL, 2011b. Available at: http://www.comie.org.mx/congreso/memoriaelectronica/v11/docs/area_12/0230.pdf. Accessed on: 22 dez. 2020

MATEOS CORTÉS, Laura Selene. La formación de gestores interculturales: jóvenes profesionistas egresados de la Universidad Veracruzana Intercultural. Revista Interamericana de Educación de Adultos, v. 37, n. 2, p. 65-81, 2015.

MATEOS CORTÉS, Laura Selene. Indigenous Youth Graduating from Intercultural Universities: capability building through intercultural higher education in Veracruz, Mexico. Journal of Intercultural Studies, v. 38, n. 2, p. 155-169, 2017. MATEOS CORTÉS, Laura Selene; DIETZ, Gunther. Universidades Interculturales en México. In: BUSQUETS, María Bertely; DIETZ, Gunther; DÍAZ TEPEPA, Guadalupe (Coord.). Multiculturalismo y educación 2002-2011. Mexico: COMIE; ANUIES, 2013. P. 349-381.

MATEOS CORTÉS, Laura Selene; DIETZ, Gunther. How Intercultural is an "Intercultural University”? Revista Lusófona de Educação, v. 31, p. 125-143, 2016.

MATEOS CORTÉS, Laura Selene; DIETZ, Gunther; MENDOZA ZUANY, R. Guadalupe $i$ Saberes-haceres interculturales? Experiencias profesionales y comunitarias de egresados de la educación superior intercultural veracruzana. Revista Mexicana de Investigación Educativa, v. 21, n. 70, p. 809-835, 2016.

MATEOS CORTÉS, Laura Selene; MENDOZA ZUANY, R. Guadalupe; DIETZ Gunther (2013) Diversidad e interculturalidad en la educación superior convencional. In: BUSQUETS, María Bertely; DIETZ, Gunther; DÍAZ TEPEPA, Guadalupe (Coord.). Multiculturalismo y educación 2002-2011. Mexico: COMIE; ANUIES, 2013. P. 307-347.

MATO, Daniel (Ed.). Instituciones Interculturales de Educación Superior en América Latina. Caracas: UNESCO-IESALC, 2009.

MATO, Daniel. Universidades indígenas de América Latina: logros, problemas y desafíos. Revista Andaluza de Antropología, v. 1, p. 63-85, 2011.

MATO, Daniel. Educación superior y pueblos indígenas: experiencias, estudios y debates en América Latina y otras regiones del mundo. Revista del Cisen Tramas/Maepova, v. 6, n. 2, p. 41-65, 2018.

MESEGUER GALVÁN, Shantal. Imaginarios de futuro de la juventud rural educación superior intercultural en la Sierra de Zongolica, Veracruz, México. 2013. Thesis (Ph.D. in Antropología y Bienestar Social) - Universidad de Granada, Granada, 2013.

NAVARRETE-CAZALES, Zaira; ALCÁNTARA-SANTUARIO, Armando. Universidades interculturales e indígenas en México. Revista Lusófona de Educação, v. 31, p. 145-160, 2016

NAVARRO MARTÍNEZ, Sergio I. Discursos y prácticas de la educación intercultural: análisis de la formación de jóvenes en el nivel superior en Chiapas. 2016. Thesis (Ph.D. in Ciencias Sociales y Humanísticas) - Universidad de Ciencias y Artes de Chiapas, San Cristóbal de las Casas, 2016.

OLIVERA RODRÍGUEZ, Inés. ¿Desarrollo o bien vivir? Efecto educativo en un contexto intercultural: experiencias de mujeres indígenas de Huazuntlán, Veracruz. 2013. Tesis de maestría (Maestría en Antropología) - Universidad Nacional Autónoma de México, Ciudad de México, 2013. 
OLIVERA RODRÍGUEZ, Inés. Etnografía colaborativa de la evaluación de la calidad en dos sedes de la Universidad Veracruzana Intercultural como un (des) encuentro de políticas públicas. 2019. Thesis (Ph.D. in Antropología) - Universidad Nacional Autónoma de México, Ciudad de México, 2019.

PERALES FRANCO, Cristina; MCCOWAN, Tristan. Rewiring higher education for the Sustainable Development Goals: the case of the Intercultural University of Veracruz, Mexico. Higher Education, Netherlands, n. 81, p. 69-88, 2021. Available at: https://doi.org/10.1007/s10734-020-00525-2. Accessed on: 22 Dec. 2020.

RAMOS CALDERÓN, José Antonio. Política educativa de inclusión en la educación superior: el caso de las Universidades Interculturales. In: RUEDA BELTRÁN, Mario; ÁLVAREZ ARELLANO, Lilian (Coord.). Propuestas para transformar el Sistema Educativo Mexicano. Mexico: UNAM, 2018. P. 58-68.

ROJAS CORTÉS, Angélica; GONZÁLEZ APODACA, Érica. El carácter interactoral en la educación superior con enfoque intercultural en México. LiminaR, v. 14, n. 19, p. 73-91, 2016.

SALMERÓN CASTRO, Fernando I. Prólogo. In: GONZÁLEZ GONZÁLEZ, Floriberto; ROSADO-MAY, Francisco J.; DIETZ, Gunther (Ed.). La gestión de la educación superior intercultural: retos y perspectivas de las universidades interculturales. Chilpancingo: Ediciones Trinchera, 2017. P. 9-16.

SCHMELKES, Sylvia. Creación y desarrollo inicial de las universidades interculturales en México. In: MATO, Daniel (Coord.). Diversidad Cultural e Interculturalidad en Educación Superior: experiencias en América Latina. Caracas: UNESCO-IESALC, 2008. P. 329-337.

SCHMELKES, Sylvia. Programas de formación académica para estudiantes indígenas en México. In: AUPETIT, Sylvie Didou; ALLIONE, Eduardo Remedi (Coord.). Educación Superior de Carácter Étnico en México. Mexico: Senado de la República, CINVESTAV, 2011. P. 65-78.

SHORE, Chris; WRIGHT, Sue. Governing by numbers: audit culture, rankings and the new world order. Social Anthropology / Anthropologie Sociale, v. 23, n. 1, p. 22-28, 2015.

TAPIA GUERRERO, Luis Arturo. El subsistema de universidades interculturales en México. Revista Latinoamericana de Estudios Educativos, v. XLVI, n. 1, p. 7-50, 2016.

VARGAS MORENO, Paola A. Más allá de la dicotomía "desde arriba” vs. “desde abajo": educación superior intercultural en Ecuador y México. apuntes para la construcción de un campo. 2020. Thesis (Ph.D. in Ciencias Políticas Y Sociales) - UNAM, Ciudad de México, 2020.

Gunther Dietz possui mestrado e doutorado em antropologia pela Universidade de Hamburgo. Atualmente é professor pesquisador em Estudos Interculturais na Universidad Veracruzana, onde trabalha com etnicidade, interculturalidade e educação intercultural / inter-religiosa.

ORCID: https://orcid.org/0000-0002-1487-2673

E-mail: guntherdietz@gmail.com

Laura Selene Mateos Cortés é pesquisadora educacional, filósofa e antropóloga na Universidad Veracruzana e Universidad de Granada. É doutora em antropologia pela Universidad de Granada e professora pesquisadora na Universidad Veracruzana em educação superior intercultural. 
Rumo a um Sistema de Ensino Superior para Estudantes Indígenas?

ORCID: https://orcid.org/0000-0002-1093-4654

E-mail: lauramat@gmail.com

Editor-responsável: Luís Armando Gandin

Este é um artigo de acesso aberto distribuído sob os termos de uma Licença Creative Commons Atribuição 4.0 Internacional. Disponível em: <http:// creativecommons.org/licenses/by/4.0>. 